RESEARCH ARTICLE

\title{
The Access Network: Supporting the Construction of Social Justice Physics Identities Through Student Partnerships
}

\author{
*Daniel Reinholz ${ }^{a}$, Adriana Corrales ${ }^{b}$, and Amelia Stone-Johnstone ${ }^{b}$ \\ a: Department of Mathematics \& Statistics, San Diego State University, USA. \\ b: Center for Research in Mathematics and Science Education, San Diego State University, USA \\ Contact: daniel.reinholz@sdsu.edu
}

\begin{abstract}
This paper explores the intersections of Students as Partners (SaP) and identity development. While identity and sense of belonging are known to be key factors for predicting success and persistence in STEM, less is known about how student partnerships can provide space for students to develop their identities. To explore this space, we focus on the Access Network, a coalition funded by the National Science Foundation (NSF) of student-run programs that aims to improve equity in the physical sciences. Qualitative interviews with six student participants showed how SaP created opportunities for students to develop social justice physics identities, which allowed them to bridge traditional notions of what it means to be a physicist with their own social justice commitments. This paper contributes to the rapidly growing SaP literature by studying student partnerships at the scale of a national network of institutions, which contrasts studies that focus on more localized contexts, such as teaching and learning in a single classroom.
\end{abstract}

\section{KEYWORDS}

culture, identity, physics education, social justice, STEM

Participation in the physical sciences is disproportionately white and male: bachelordegree attainment remains disproportionately low for students of color and white women (National Science Foundation [NSF], 2018). In the United States, these inequities are perpetuated by a variety of systemic factors, including: institutional racism (Harper, 2012; McGee \& Bentley, 2017), ideologies (Shah, 2017; Traweek, 1988), and interpersonal harassment (Kelsky, 2017). Thus, it is an exclusionary culture (Behrman, 2018; Ong, 2005) - not deficits in students themselves - that denies students access to identity development that is 
crucial for persistence in science, technology, engineering, and mathematics (STEM) fields (Hand \& Gresalfi, 2015; Stets, Brenner, Burke, \& Serpe, 2017).

Like others before us (Martin, 2009; Rosa \& Mensah, 2016), we categorically reject deficit-based perspectives of students. Instead, we adopt an anti-deficit stance, and seek to understand the role of building meaningful partnerships with students from historically marginalized groups. Through partnerships, students can improve their own education and change the system itself (Dunne \& Zandstra, 2011; Healey, 2016). This paper explores student partnerships in the Access Network, a coalition of programs that promote equity in the physical sciences.

Although prior research describes student partnerships within individual Access programs (e.g., Dounas-Frazer, Hyater-Adams, \& Reinholz, 2017; Sabella, Van Duzor, \& Davenport, 2016; Zaniewski \& Reinholz, 2016), this is the first paper describing partnerships at the network level. In particular, we focus on how Access supported students to develop a social justice physics identity, which integrates commitments to social justice and a traditional physics disciplinary identity. Through active engagement in anti-oppression work, social justice physicists attend to equity issues in the discipline and in society more broadly. To explore the impact of the network on identity development, we conducted qualitative interviews with six student fellows who had taken on leadership roles in the network. We address the following research question: how do student partnerships in the Access Network support students to develop social justice physics identities?

This manuscript makes a number of important contributions to the SaP literature (cf. Mercer-Mapstone et al., 2017). First, it addresses the identified need for more research on inter-institutional partnerships. Second, it addresses multiple types of student partnerships in a single context (i.e., among students, postdocs, and faculty). Third, our focus on identity development highlights the potential for partnerships to improve equity in the physical sciences.

\section{BACKGROUND}

\section{Identity}

Given the close relationship between learning and identity development (Hand \& Gresalfi, 2015; Nasir, 2002), learning physics requires opportunities for students to construct identities as physicists. Without such opportunities, students may fall victim to negative stereotypes that reduce belonging and inhibit persistence (Good, Rattan, \& Dweck, 2012; Master, Cheryan, \& Meltzoff, 2016). In contrast, positive identities increase motivation and persistence (Fraser \& Ward, 2009; Stets et al., 2017; Woodcock, Hernandez, \& Schultz, 2016). In addition, identity is an important construct that has been taken up in the SaP literature (see Matthews et al., 2019).

Identities are dynamic, context-dependent, and individually and socially constructed (Eccles, 2009; Holland \& Cole, 1995; La Guardia, 2009; Oyserman, Bybee, \& Terry, 2006).

Through social interactions, one is able to try out a particular identity and receive feedback that can validate or invalidate that identity (Pasupathi, Stallworth, \& Murdoch, 1998; Tice, 1992). While students do have individual agency in developing their own identities, they do so in the chilly climate in STEM (Cech \& Waidzunas, 2018; Seymour \& Hewitt, 1997). 
To operationalize identity, we draw from a recently published framework on race and physics identity (Hyater-Adams, Fracchiolla, Finkelstein, \& Hinko, 2018), which consists of six constructs of interest drawn from two other frameworks (Hazari, Sonnert, Sadler, \& Shanahan, 2010; Nasir, 2011). This framework highlights that there is not a singular "physics identity" but rather a multitude of possible physics identities that individuals construct in ways that are consistent with their other identities (e.g., racial identities, gender identities). In this paper, we focus on how students integrate their multitude of identities to develop as social justice

physicists. The six constructs are now described, and examples are given below in Table 2 of the methods section.

Competence relates to whether or not a student believes that they can perform and understand required tasks. Interest focuses on reasons or experiences that contribute to a student becoming passionate about physics. Recognition relates to how and whether or not a student is seen as a scientist by others (e.g., peers, mentors). These constructs center on the individual, focusing on what students think about themselves, or how they are seen by others. The other three constructs focus on the resources an environment provides that may support or inhibit identity development. Relational resources are relationships with others that impact a student's connection to physics. Ideational resources are aspects of an idea (e.g., narrative, selfperception, value judgement) that connect a student to physics and what it means to be a physicist. Finally, material resources are material things (e.g., a student program) that provide access to physics.

These six constructs are distinct but overlapping. For example, a relationship with a particular social justice physicist that provides mentorship and support (i.e., a relational resource) could also serve as an ideational resource, because it validates a non-traditional physics identity. Similarly, a single experience could support identity development along multiple constructs. For example, an early research experience could support both interest and recognition in physics (Laursen, Hunter, Seymour, Thiry, \& Melton, 2010).

\section{Students as Partners}

We define a student partnership as "a joint endeavor to shape and influence university teaching and learning" (Matthews, 2016, p. 3). In Access, students partner with other students (undergraduate and graduate), postdoctoral researchers, faculty, and staff. Student partnerships at Access sites create opportunities for students to meaningfully engage the discipline of physics through innovative courses, research opportunities, and community building (see, e.g., Albanna, Corbo, Dounas-Frazer, Little, \& Zaniewski, 2013). The goal of network-level partnerships is to enhance these activities at individual sites, and also to build student community and leadership across sites.

Student partnerships provide fertile ground for students to engage in the complex, socially negotiated process of identity development. They provide opportunities for students to authentically be a part of a physics community and to receive social validation from that community. Because Access explicitly integrates physics and social justice, it provides a space for students to build identities that honor their own social justice commitments. These partnerships are organized around core values, including: authenticity, inclusivity, reciprocity, 
empowerment, trust, challenge, and community (Healey, Flint, \& Harrington, 2014; Healey et al., 2014).

These partnerships also involve a genuine effort for power sharing (Matthews, 2017). This is achieved by engaging students through a variety of clearly defined roles (Bovill, 2017) and by paying students for their work (Mercer-Mapstone et al., 2017). In Access, student partners (called "fellows") and faculty receive comparable stipends ( $\$ 500$ per semester for fellows; \$1000 or \$2000 per year for faculty). These comparable stipends signal that students and faculty are equally valued. This paper focuses specifically on students; the impact on Access leaders is beyond the scope of this study.

\section{The Access Network}

The oldest Access site is the nationally-recognized Berkeley Compass Project (American Physical Society, 2012; Heron \& McNeil, 2016), which served as a model program for the network. Compass was founded in 2006 and is led by graduate and undergraduate students at the University of California Berkeley. Compass has provided a variety of services including: a summer program, inquiry-based courses for students, mentorship opportunities, and student research opportunities (see, e.g., Albanna et al., 2013; Berggren, Gandhi, Livezey, \& Olf, 2018; Dounas-Frazer, Lynn, Zaniewski, \& Roth, 2012). When Access was formed with NSF funding in 2015 , it consisted of six programs that were inspired by Compass. These programs are also organized around student leadership, and the details of individual programs are described in a variety of publications (Cammarata \& Owens, 2017; e.g., Marks \& Dawod, 2016; Rainey, Dounas-Frazer, \& Huynh, 2016; Reinholz \& Dounas-Frazer, 2017; Sabella, Mardis, Sanders, \& Little, 2017).

Access programs create opportunities for authentic engagement with physics while simultaneously meeting the needs of their local populations. All sites intentionally recruit and serve student populations with significantly higher fractions of women and/or students of color than typical physical science departments nationally. Sites support other forms of diversity, too (e.g., IMPRESS has a significant population of Deaf and hard-of-hearing students, $70 \%$ of Sundial students were in the bottom $30 \%$ of their entering freshmen class for academic preparation, and Chi-Sci Scholars is located at a Predominantly Black Institution with many commuter students). While some of these programs have faculty leaders, many are completely studentrun.

The network has four main activities: (a) the Access Assembly, (b) network communication, (c) documentation of models, and (d) dissemination. The Access Network leadership team is comprised of current and former leaders from member programs (typically early-career faculty members and postdoctoral researchers, called "core organizers"). Each network activity is also supported by student members of the network (fellows), who receive honoraria for their work. This paper focuses on the Access Assembly and network communication.

The annual Access Assembly is a three-day meeting that supports community building and the sharing of best practices across sites. It also supports all members to deepen their understanding of social justice. The Assembly is planned by approximately six student assembly fellows in partnership with two network core organizers. The fellows help with planning, 
ranging from logistics to designing sessions. They also help run the Assembly and incorporate feedback from participants in an ongoing fashion as the assembly commences (e.g., through daily debriefs). They are also involved in conflict resolution. For instance, after the inaugural Assembly at Arizona State University, a core organizer and a team of about five students from various sites formed a task force to address a conflict and make recommendations - many of which were taken up-to the network leadership. These types of authentic partnerships are hugely important for student ownership of the Assembly and also for building trust between leaders and members.

Network communication is supported by network fellows who help connect local programs to the network as a whole. These fellows support bi-lateral communication through regular virtual meetings. Over the three funded years of Access, the role of these students has evolved, to focus on other efforts such as sharing engagement with Access through blog posts, updating the Access website, coordinating a winter workshop between Assemblies, and coordinating student travel to other conferences like the Annual meeting of the Society for Advancement of Chicanos/Hispanics and Native Americans in Science (SACNAS). These fellows also partner with two core organizers, who collaborate with a group of approximately nine fellows at a time. Many network fellows also attend the assembly, and it is also common for fellows to transition between the roles of assembly fellow and network fellow in subsequent years.

\section{METHOD}

\section{Researcher positionality}

The three-member research team was led by an Access Network founder and core organizer who is not currently associated with a local program. This organizer identifies as a white man, and is familiar with the day-to-day operations of programs, through interaction with three programs. The other two team members were graduate students who were not affiliated with Access. The graduate student who conducted interviews identifies as a Latinx woman, and she had personal experiences engaging in student-faculty research partnerships as an undergraduate student. The third team member identifies as a Black woman.

\section{Participants}

An email was sent to leaders at local Access sites to recruit past and present fellows. Of the approximately 40 past and present fellows in the network, six agreed to participate without receiving any compensation. Participants' self-reported demographics are given in Table 1.

\section{Table 1. Participant demographics}

\begin{tabular}{llll} 
Name & Race & Gender & Fellow Role \\
\hline Alex & N/A* & N/A* & Network \\
Haley & Black & Woman & Assembly \\
Michael & Latinx/Mexican & Man & Network \\
Peter & Asian/Caucasian & Man & Network \\
Taylor & Hispanic & Woman & Assembly \\
Tommy & African American/Black & Man & Network
\end{tabular}

*Alex did not answer the questions related to race or gender. 


\section{Data sources}

This paper analyzes transcripts of interviews with student fellows. Interviews were conducted virtually using Zoom conferencing software, and the interview protocol was organized around Hyater-Adams et al.'s physics identity framework (2018). The 45-minute interviews had five parts: (a) introductory information, (b) physics goals, (c) physics identity, (d) personal identity and intersections with physics identity, and (e) closing and summary. Sample questions include: "To what extent do you see yourself as a physicist?" and "Is there any aspect of what it means to you to be a physicist, that you think is particularly important but may not align with your perception of a stereotypical physicist?" The study received Institutional Review Board approval before any data were collected.

\section{Analytic methods}

Our unit of analysis was a single interview question, including all follow-up questions (with 20 questions total). Each unit was coded to indicate the presence or absence of the six constructs listed in Table 2 (cf. Hyater-Adams et al., 2018).

Table 2. Codes used for the present study

\begin{tabular}{|c|c|c|}
\hline Code & Description & Example \\
\hline Recognition & $\begin{array}{l}\text { Being recognized as a physicist or } \\
\text { physics person. }\end{array}$ & $\begin{array}{l}\text { "The fact that I spent more years in my } \\
\text { life studying physics in college has } \\
\text { stamped that identity onto me, and } \\
\text { others do perceive me as that." }\end{array}$ \\
\hline Competence & $\begin{array}{l}\text { Belief in one's ability to understand } \\
\text { and perform tasks in physics. }\end{array}$ & $\begin{array}{l}\text { "I would say overall I'm a pretty good } \\
\text { physics student." }\end{array}$ \\
\hline Interest & General interest in the physics field. & $\begin{array}{l}\text { "I've always been interested in } \\
\text { understanding how we can use } \\
\text { materials for other electronic devices." }\end{array}$ \\
\hline $\begin{array}{l}\text { Relational } \\
\text { resources }\end{array}$ & $\begin{array}{l}\text { How relationships with others } \\
\text { impact one's connection to physics. }\end{array}$ & $\begin{array}{l}\text { "I felt welcomed in physics, where } \\
\text { everyone's just happy to be there." }\end{array}$ \\
\hline $\begin{array}{l}\text { Ideational } \\
\text { resources }\end{array}$ & $\begin{array}{l}\text { Ideas about physicists. This includes } \\
\text { personality traits, perceptions, and } \\
\text { values, and one's own position. }\end{array}$ & $\begin{array}{l}\text { "I guess when I think of a typical } \\
\text { physicist I think of somebody working } \\
\text { at a blackboard or something, trying to } \\
\text { solve problems or work out math } \\
\text { problems." }\end{array}$ \\
\hline $\begin{array}{l}\text { Material } \\
\text { resources }\end{array}$ & $\begin{array}{l}\text { Material things such as programs, } \\
\text { communities, organizations, } \\
\text { funding. }\end{array}$ & $\begin{array}{l}\text { "[I] wouldn't have flourished, so to } \\
\text { speak, without all the support that I } \\
\text { had with [Local Program] and Access } \\
\text { Network." }\end{array}$ \\
\hline
\end{tabular}

\section{STUDENTS ARE PARTNERS}

Although students were not asked explicitly if they felt like partners, it emerged organically during the interviews when students described their roles. For instance, Alex described their experiences working as a network fellow: "it's supposed to be like nobody's the 
president or something like that, so nobody has more power than anybody else. Even our mentors. . . ultimately let us make the decisions." Here Alex describes a feeling that students and mentors have equal decision-making power. Similarly, other network fellows such as Michael mentioned that he was "in charge of Access and site communication," and Tommy said he helped "make decisions for the Access Network." Their language indicates that students felt like they had the authority to make meaningful decisions. Another fellow, Taylor, described her experiences as an assembly fellow:

Meeting every week and talking on video conferences with other people at other sites, planning the Assembly with all of them, working together to get things accomplished, especially working from distant locations. .. it was really good experience just working with other people.

Here Taylor describes a variety of interactions with other fellows that resulted in the planning of the Assembly. The experience Taylor describes was a genuine collaboration, working with students to plan the assembly and "get things accomplished." It was not merely a tokenized experience for the students. Haley also described herself as an "Assembly coordinator," which meant that she was "one of the planners" for the meeting. These examples showcase student ownership of their work in Access. We now turn to how partnerships supported students to develop their identities.

\section{SOCIAL JUSTICE PHYSICS IDENTITY DEVELOPMENT Summary of codes}

Table 3 summarizes the frequency of codes across categories. While all of the categories were present in the interviews, we note that ideational resources were the most commonly coded. This is due to the relatively broad way that these resources are defined, which means that they were often coded at the same time as other identity constructs.

Table 3. Frequency of codes

\begin{tabular}{lcccccc} 
Participant & Recognition & Competence & Interest & Relational & Ideational & Material \\
\hline Alex & 3 & 2 & 3 & 2 & 9 & 7 \\
Haley & 3 & 1 & 5 & 3 & 12 & 11 \\
Michael & 5 & 2 & 3 & 2 & 15 & 9 \\
Peter & 4 & 2 & 2 & 2 & 9 & 3 \\
Taylor & 2 & 3 & 2 & 6 & 9 & 6 \\
Tommy & 4 & 3 & 2 & 2 & 12 & 10 \\
Total & $\mathbf{2 1}$ & $\mathbf{1 3}$ & $\mathbf{1 7}$ & $\mathbf{1 7}$ & $\mathbf{6 5}$ & $\mathbf{4 6}$
\end{tabular}

The results of coding are split into six sections, one for each identity construct. In contrast to studies that tell narrative stories of identity development (e.g., Hyater-Adams et al., 2018), we focus on the role of Access more generally on identity development. Thus, we do not make strong claims about the identity of any individual participant, but rather the capacity of these inter-institutional student partnerships to support identity development more broadly. 


\section{Material resources}

Access provides students with a variety of material resources. This happens through local programs, and also through network-level interactions. Haley described a variety of these benefits:

I would've had no idea how to do science without the Access Network. I wouldn't have known that I should've gone out and gotten research positions in my undergrad. I wouldn't have had a publication under my belt in undergrad. I wouldn't have gone to conferences and presented as an undergrad, and gotten so many different skills under my belt. I wouldn't have learned programming. I would have had none of this without [Local Program] and the Access Network. I would've just gone to school, gone to class, gotten my degree. Because now I have a full resume because of that, you know? I can go and say look at all these things I did. I got published, I was a TA, I did research. ... I'm so grateful that I've had the Access Network and [Local Program] interject in the middle of my undergrad. It was the best thing that could have happened.

Haley refers to having published a paper as an undergraduate, which was a result of the research experiences she participated in as a part of her local program. She further describes how her participation in Access helped reveal the implicit yet critical aspects of being a physics student (Jackson, 1968). This is a key aspect of equity, because some groups of students may be much less likely to have access to this implicit knowledge, due to their cultural and social backgrounds (see, e.g., Harrell \& Forney, 2003). By providing material resources to help Haley succeed, Access supported the development of her physics identity. As Haley's quotes describe, we can see the ways that her partnership in a community of physicists provided her with opportunities to draw on material resources (e.g., research experiences, presenting at conferences, learning programming).

The existence of the network itself can also be seen as a valuable material resource. Access itself provides a community and a space for students to integrate a commitment to social justice with their engagement with physics. It provides a venue in which social justice is a core commitment. For example, Michael reflected on his experiences at the Assembly:

They did give me a lot of good advice in terms of keeping the passion for diversity alive. It's easy at the Access Assembly to get really pumped about doing all these things, [and Access members] gave me some advice about how to go back to my local site and just keep it going, I suppose, keep the energy up, and draw it out so that the program doesn't fizzle out.

Here Michael describes how it was "easy" to get excited about social justice at the Assembly, but also that it is easy for the energy to dissipate when he returns home where social justice is not a primary focus. This draws attention to the value of Access in creating inter-institutional partnerships, because it allowed Michael to work with others who were also committed to social justice. In addition, Michael stated that he felt "like physicists play a huge part" in outreach and promoting diversity at his own institution, which indicates that his connection to 
the social justice physics identity extends beyond his time at the Assembly. In this way, the Assembly serves as an environment for cultivating a community focused on physics and social justice both as a material and ideational resource, as we describe below.

\section{Ideational resources}

Ideational resources help define what it means to be a physicist and what is valued in physics. For example, Tommy described how his partnership allows him to engage with a version of physics that's not just about doing research, but where social justice is valued too:

I feel like a lot of the physicists that I work with. . . the ones who are not really part of [the local program], I feel like everyone is very much into their research, into their work, and aren't very open to talking about some of these other issues that come up. I kind of had a feeling that these other kinds of physicists exist, but going to the Access [Assembly] and seeing other people who, some of them do research and also are part of the Access Network, or they have other roles on their campus and are still core organizers of the Access Network, I think that changed my view a little bit. It kind of showed me that it is possible to still focus on your research and be invested in your research and still be involved in these more social justice type things I guess.

In this way, the existence of the network provides a space that supports a different notion of what it means to be a physicist, because the Access leaders are recognized as physicists, and they do not necessarily conform to the traditional idea of what it means to be a physicist.

Another student, Taylor, described how her participation in Access helped her adjust her expectations about what it meant to belong in physics:

I think I struggled a lot at the beginning with feeling like I wasn't good enough to be in physics. But after attending the Access Assembly and listening to talks about imposter syndrome and stuff like that, and also just realizing that it's okay if you feel super aware that you don't fit into the group of people in your class and stuff like that, it doesn't mean that you're not good enough or you don't fit in, it's just a product of physics being not diverse and not inclusive. I think since learning those things it's really helped me to push those ideas out of my head and just work through them.

Here Taylor describes self-doubt associated with her struggles as a physics student. In this case, her partnership within Access provided another lens ("that physics is not diverse and not inclusive") through which she could view those experiences. This helped normalize self-doubt as a consequence of a non-inclusive physics culture, instead of as a signal that she does not belong.

\section{Relational resources}

Access also provides relational resources through community building. For example, Taylor described having role models "who have also faced diversity" and who are still "actually 
physicists." This indicates that Access helped her build relationships with people that she more closely identified with, which is a valuable support for her own identity development, which she explained in the following excerpt:

I'd say the majority of people in Access are actually physicists, so during the Assembly I talked to a lot of them about their paths to where they are now. Because a lot of the organizers are professors or postdocs currently, so talking to them about how they got to where they are, what kind of physics they did, stuff like that. It's super helpful to have mentors as well. That's another big thing that I think Access has provided, other people who also have faced adversity and issues within physics and are succeeding. It's really helpful to see role models.

Taylor describes these personal connections-opportunities to see the struggles of others-as meaningful resources that motivate her to succeed. Alex also noted the importance of mentors: "I mean [network fellow leader] has helped me. . he's definitely helped me out, talking me through stuff, advice and stuff." Similarly, Peter described receiving mentorship from one of the core organizers, and said that he "still consider[s] [the core organizer] to be one of my mentors. He teaches me how to effectively lead and how to run a program like Compass." As these quotes highlight, participation in the network provided students with opportunities to receive meaningful mentorship. Most of the current leaders in Access got involved earlier in their careers when they were still students. As they progressed in their careers, they have provided mentorship to network leaders in Access, while leaders at local sites also mentored students who were just beginning their studies (Zaniewski \& Reinholz, 2016). In this way, the network and local sites aim to build relationships and provide mentoring at many levels.

\section{Recognition}

STEM fields are known to often be unwelcoming, and students may not receive much positive encouragement or recognition from their professors (Seymour \& Hewitt, 1997). As Taylor described above, the fellows generally did see members of Access as physicists, so when they receive positive recognition from members of Access, it provides an opportunity to validate their identities from a member "in the group of physicists." Consider the following statement made by Alex when asked if they received recognition from professors or superiors: "Not really. I guess most of the positive recognition I get would be from Access people." While some students mentioned receiving support from friends and family, many students noted a lack of recognition from both professors and peer groups. For example, Tommy talked about his experiences sharing his career aspirations with strangers: "I've definitely had those Uber, Lyft rides where you have the small talk, 'oh, what do you do?', 'I'm a grad student in physics,' 'What? You do physics?! That's so hard! Are you serious?'” Although it is not explicitly stated, the undertone of the Uber driver's response is that as a Black man, Tommy may not belong in physics. Tommy makes this more explicit when he describes his own "imposter syndrome" and feeling "left out" as "one of two black students" in his entire department. Ultimately, Tommy rejects these stereotypes, by stating that he does not "really care" how "other people see him," because he is "doing this for [himself]." Tommy's awareness of and rejection of stereotypes is 
consistent with research showing how students navigate problematic stereotypes in mathematics (Shah, 2017). Connecting to Tommy's description above about the Access Assembly, we find some evidence that Access provides a place where students can challenge and reject such stereotypes.

\section{Competence}

Partnerships can also support students to see themselves as competent physicists. For instance, Taylor described her struggles with transitioning to physics, and not feeling like she knew what was needed to succeed:

I think I struggled a lot my freshman year, coming from a small school to a big university. I often felt like I didn't know how to study, or the way that I thought was studying wasn't working out the way like I was hoping it would. . . I think [that after attending the Assembly] I feel a lot more comfortable as a physics major just because I know that this is what I'm interested in and I'm willing to work for it, and I'm not so much worried about if I'm inherently smart enough to be a physics major anymore.

Taylor described her attendance at the Assembly, and has mentioned previously, understanding the imposter syndrome as a byproduct of the non-inclusive culture of physics helped her doubt her competence less and work towards her goals as a physicist. Normalizing and empathizing with struggle is a cultural value in some Access programs (see, e.g., Reinholz \& Dounas-Frazer, 2017), which can be shared across sites in the Assembly.

Similarly, Alex described doubt that they could "pull off" what physics required:

Before I got involved with [Access program] I didn't really have any idea what it took to be a physicist, I just kind of thought it would be cool, but I had a lot of doubts if I could pull that off or not. But then talking to all the people who have done it and just seeing that it's very do-able.

As Alex describes, their connections and partnerships with others helped them readjust their own doubts, and instead recognize that they was competent enough to be a physicist. In this way, we see that part of students developing their own confidence as physicists was their feeling of connection to a like-minded group of social justice-oriented physicists.

\section{Interest}

Most students interviewed were interested in physics before they got involved with Access. Nevertheless, Access provided opportunities for students to incorporate their other interests (e.g., social justice commitments) with their interest in physics. This helped them see opportunities to get involved in other potential careers with physics. Haley described how her interactions got her interested in teaching:

I kind of got more interested in teaching with more of the outreach that I was doing with [Access Program] and Access Network, because I saw how much it affected the 
people when we were doing outreach. I'm going to do this [teaching] for a few years, and then hopefully l'll be able to go back and do my PhD later.

The fact that Haley views teaching and outreach as an important part of being a physicist speaks to the socially conscious physics identity that Access helped students develop. Haley elaborated further, talking about how it was important for her work to impact other girls in STEM so that they could pursue their own interests: "I have to stand up for the other little girls in the world who maybe are being told they can't do what it is that they're interested in, or that they shouldn't." Here, Haley is able to use her success to help create opportunities for other women to be successful. Similarly, Tommy described his desire to help others who are interested in physics to persist and achieve their goals:

I've been involved with a lot of STEM diversity type work. . . I feel like growing up I was around a lot of people who found this kind of stuff interesting, but a lot of people that I knew, at least where I went to school growing up, didn't actually go into those fields. Some didn't really go to college at all. And I feel like there are a lot of students who are interested in getting into this kind of stuff but don't have the same opportunities as other students.

In both of these situations, Access normalized the identity of a social justice physicist, which created space for students to develop their identities. The fact that students were able to identify as physicists in this way broadened the notion of what it meant to know and do physics in a way that was more inclusive and had the potential for greater social impact.

\section{Intersecting identities}

Although the above six constructs are presented separately, they are all interrelated. For example, the material resource of the Access Assembly provides an important site for students to be recognized by leaders in the community, which can further spark their interest and feelings of competence. The constructs also intersect with racial and gender identities, which was a finding that emerged during data analysis. For example, Taylor described how she "didn't fit the stereotype for who physics majors were," because some people perceive that "minorities aren't as good at science or aren't as good at math." She continued to describe her intersecting identity as a woman, which "made it a little more difficult" to succeed in physics. For this reason, it is important to look at identity development holistically and understand how a given program (like Access) may or may not support aspects of identity development. In Access, the explicit focus on social justice normalized conversations about race and gender that provided more space for students to bring these identities to their work as physicists.

Race also impacts cultural practices. For example, Tommy noted in that in his family they "speak with a lot of slang," and this was something that he struggled with when trying to communicate in formal academic language as a new physics student. Here Tommy describes a conflict between the English used in the Black household he grew up in and white academic culture. We found evidence in the interviews quoted above that Access provided a different type of space for Tommy to negotiate these two sometimes conflicting identities. 
Fellows also articulated ways that their identities could privilege them above other students. For example, Peter noted that his own identities likely benefited him, because "the majority of physicists are white and male." Similarly, Tommy mentioned that he felt he was "treated with more respect than female students." In particular, he found that when his friends who identified as women shared "things that they've experienced," it helped him see the "bigger picture." As we have seen, intersecting identities informed students' development of social justice physics identities in Access.

\section{DISCUSSION}

The Access Network provides an important example of how student partnerships can be formed in an inter-institutional network. In contrast to short-lived partnerships that may end after a semester or year, many participants involved in local Access sites and at the network level may engage for many years. The longer that students engage, the more they are able to take on increasingly complex leadership roles. This provides an opportunity for ongoing mentoring and development through partnership. We view this as a truly authentic form of student partnership (Matthews, 2016), in which students have meaningful power sharing with faculty and postdoctoral researchers (Matthews, 2017).

Students benefited from partnerships with other students, postdoctoral researchers, and faculty. Because Access supports inter-institutional collaboration, it provides students opportunities to meet peers across the country that have similar aspirations, backgrounds, and social justice commitments. This is crucial, because students may be more isolated at their home institutions. In addition, the student-faculty partnerships support meaningful mentoring for the students. Thus, Access provided ample social feedback that could help validate students' identities (Pasupathi et al., 1998). Although it is not the focus of this article, these partnerships have the potential to enhance the capacity of the faculty partners to enact their goals of equitable improvement to physics. This is a potential area for future inquiry.

All of the participants noted how Access supported their identity development. The racialized identity framework and its six constructs were useful for capturing the various ways in which students had meaningful connections to Access. Fellows highlighted the valuable resources they received, in terms of material support, close connections to mentors and peers, and the importance of a social-justice focused community. Fellows also described how Access helped provide recognition and supported beliefs of their own competence. When it came to interest, fellows mostly used Access as a space and motivation to support the interest of others as they came into their program with some interest in science.

A limitation of this study is that only six students were interviewed. The perceptions of students were largely positive. It is likely that students do not have uniformly positive reactions to Access, but those who may have had some issues would be less likely to participate in the interviews. Moreover, it was not always possible to disentangle the impact of partnerships within the network as compared to partnerships that exist within the local programs. For this reason, we cannot make strong claims about the specific benefits of leadership roles in the Access Network as separate from participation in local programs. Nevertheless, we do find evidence that the combination of the network and local programs was valuable for students. 
Despite these limitations, this paper highlights the potential of involving students as partners in a large national network. As partners in the network, students developed identities as social justice physicists. Thus, it is noteworthy that Access did not just support students to develop their identities, but to do so in a way that connected with their own backgrounds and intersecting identities. This careful attention to the development of physics identities is an important contribution for pushing the field forward towards equity in physics (cf. HyaterAdams et al., 2018). This analysis contributes to the literature on Students as Partners by showing how genuine partnerships can support student identity development in a way that is aligned with the needs and background of students. Because identity development is central to learning and persistence, this highlights another important aspect of student partnerships. In this way, we contribute to the growing body of research on identity development through partnerships (cf. Matthews et al., 2019).

\section{ACKNOWLEDGEMENTS}

We thank Simone Hyater-Adams and Dimitri Dounas-Frazer for their support in developing the interview protocol and for their feedback on an earlier draft of the paper. We also thank Angie Little and Gina Quan for their feedback. This study was conducted with IRB approval.

\section{NOTE ON CONTIBUTORS}

Daniel Reinholz is an Assistant Professor of Mathematics Education at San Diego State University where he studies equity and systemic change in STEM education.

Adriana Corrales is a doctoral student in the Mathematics and Science Education Doctoral (MSED) Program that is jointly administered by San Diego State University and the University of California San Diego.

Amelia Stone-Johnstone is a doctoral student in the Mathematics and Science Education Doctoral (MSED) Program that is jointly administered by San Diego State University and the University of California San Diego.

\section{REFERENCES}

Albanna, B. F., Corbo, J. C., Dounas-Frazer, D. R., Little, A., \& Zaniewski, A. M. (2013). Building classroom and organizational structure around positive cultural values. AIP Conference Proceedings, 1513(1), 7-10. https://doi.org/10.1063/1.4789638

American Physical Society. (2012). Award for improving undergraduate physics education awardees. Retrieved from http://www.aps.org/programs/education/undergrad/faculty/awardees.cfm

Behrman, J. (2018). Domesticating physics. Physics Today, 71(5), 50-56. https://doi.org/10.1063/PT.3.3922 
Berggren, C., Gandhi, P., Livezey, J. A., \& Olf, R. (2018). A tale of two slinkies: Learning about model building in a student-driven classroom. The Physics Teacher, 56(3), 134-137. https://doi.org/10.1119/1.5025285

Bovill, C. (2017). A framework to explore roles within student-staff partnerships in higher education: Which students are partners, when, and in what ways? International Journal for Students as Partners, 1(1). https://doi.org/10.15173/ijsap.v1i1.3062

Cammarata, S., \& Owens, P. (2017). The IMPRESS program at RIT. PERCoGS Newsletter, Special Issue 3, 8.

Cech, E., \& Waidzunas, T. (2018). STEM inclusion study organization report: APS. Ann Arbor, MI: University of Michigan. Retrieved from https://www.steminclusion.com/

Dounas-Frazer, D. R., Hyater-Adams, S. A., \& Reinholz, D. L. (2017). Learning to do diversity work: A model for continued education of program organizers. The Physics Teacher, 55(6), 342-346. https://doi.org/10.1119/1.4999728

Dounas-Frazer, D. R., Lynn, J., Zaniewski, A. M., \& Roth, N. (2012). Learning about nonNewtonian fluids in a student-driven classroom. The Physics Teacher, 51(1), 32-34. https://doi.org/10.1119/1.4772035

Dunne, E., \& Zandstra, R. (2011). Students as change agents-New ways of engaging with learning and teaching in higher education. Bristol: A Joint University of Exeter/ESCalate/HE Academy Publication.

Eccles, J. (2009). Who am I and what am I going to do with my life? Personal and collective identities as motivators of action. Educational Psychologist, 44(2), 78-89. https://doi.org/10.1080/00461520902832368

Fraser, J., \& Ward, P. (2009). ISE professionals' knowledge and attitudes regarding science identity for learners in informal environments: Results of a national survey. ILI Draft Report, 91104.

Good, C., Rattan, A., \& Dweck, C. S. (2012). Why do women opt out? Sense of belonging and women's representation in mathematics. Journal of Personality and Social Psychology, 102(4), 700-717. https://doi.org/10.1037/a0026659

Hand, V., \& Gresalfi, M. (2015). The joint accomplishment of identity. Educational Psychologist, 50(3), 190-203. https://doi.org/10.1080/00461520.2015.1075401

Harper, S. R. (2012). Race without racism: How higher education researchers minimize racist institutional norms. The Review of Higher Education, 36(1), 9-29.

https://doi.org/10.1353/rhe.2012.0047

Harrell, P. E., \& Forney, W. S. (2003). Ready or not, here we come: Retaining Hispanic and firstgeneration students in postsecondary education. Community College Journal of Research and Practice, 27(2), 147-156. https://doi.org/10.1080/713838112

Hazari, Z., Sonnert, G., Sadler, P. M., \& Shanahan, M.-C. (2010). Connecting high school physics experiences, outcome expectations, physics identity, and physics career choice: A gender study. Journal of Research in Science Teaching, 47(8), 978-1003. https://doi.org/10.1002/tea.20363

Healey, M. (2016). Students as partners and change agents. Healey HE Consultants: Howden. Healey, M., Flint, A., \& Harrington, K. (2014). Framework for partnership in learning and teaching in higher education. York: The Higher Education Academy. 
Heron, P., \& McNeil, L. (2016). Phys21: Preparing physics students for 21st-century careers. College Park, MD: American Physical Society: Joint Task Force on Undergraduate Physics Programs. Retrieved from http://www.compadre.org/JTUPP/docs/J-Tupp Report.pdf

Holland, D., \& Cole, M. (1995). Between discourse and schema: Reformulating a culturalhistorical approach to culture and mind. Anthropology \& Education Quarterly, 26(4), 475-490.

Hyater-Adams, S., Fracchiolla, C., Finkelstein, N., \& Hinko, K. (2018). Critical look at physics identity: An operationalized framework for examining race and physics identity. Physical Review Physics Education Research, 14(1).

https://doi.org/10.1103/PhysRevPhysEducRes.14.010132

Jackson, P. W. (1968). Life in Classrooms. New York: Holt, Rinehart and Winston. New York: Holt, Rinehart and Winston.

Kelsky, K. (2017, December 1). A crowdsourced survey of sexual harassment in the academy [Blog post]. Retrieved from https://theprofessorisin.com/2017/12/01/a-crowdsourcedsurvey-of-sexual-harassment-in-the-academy/

La Guardia, J. G. (2009). Developing who I am: A self-determination theory approach to the establishment of healthy identities. Educational Psychologist, 44(2), 90-104. https://doi.org/10.1080/00461520902832350

Laursen, S., Hunter, A.-B., Seymour, E., Thiry, H., \& Melton, G. (2010). Undergraduate research in the sciences: Engaging students in real science. San Francisco, CA: Jossey-Bass.

Marks, N.-K., \& Dawod, R. (2016). How to IMPRESS: Coordinating a large video data set for a collaborative project. DePaul Discoveries, 5(1), 22.

Martin, D. B. (2009). Researching race in mathematics education. Teachers College Record, 111(2), 295-338.

Master, A., Cheryan, S., \& Meltzoff, A. N. (2016). Computing whether she belongs: Stereotypes undermine girls' interest and sense of belonging in computer science. Journal of Educational Psychology, 108(3), 424-437. https://doi.org/10.1037/edu0000061

Matthews, K. E. (2016). Students as partners as the future of student engagement. Student Engagement in Higher Education Journal, 1(1).

Matthews, K. E. (2017). Five Propositions for genuine students as partners practice. International Journal for Students as Partners, 1(2). https://doi.org/10.15173/ijsap.v1i2.3315

Matthews, K. E., Cook-Sather, A., Acai, A., Dvorakova, S. L., Felten, P., Marquis, E., \& MercerMapstone, L. (2019). Toward theories of partnership praxis: An analysis of interpretive framing in literature on students as partners in teaching and learning. Higher Education Research \& Development, 38(2), 280-293.

https://doi.org/10.1080/07294360.2018.1530199

McGee, E. O., \& Bentley, L. (2017). The troubled success of Black women in STEM. Cognition and Instruction, 35(4), 265-289. https://doi.org/10.1080/07370008.2017.1355211

Mercer-Mapstone, L., Dvorakova, S. L., Matthews, K. E., Abbot, S., Cheng, B., Felten, P., Knorr, K., Marquis, E., Shammas, R., \& Swaim, K. (2017). A systematic literature review of students as partners in higher education. International Journal for Students as Partners, 1(1). https://doi.org/10.15173/ijsap.v1i1.3119 
Nasir, N. S. (2002). Identity, goals, and learning: Mathematics in cultural practice. Mathematical Thinking and Learning, 4(2-3), 213-247. https://doi.org/10.1207/S15327833MTL04023 6

Nasir, N. S. (2011). Racialized identities: Race and achievement among African American youth. Stanford, CA: Stanford University Press.

National Science Board. (2018). Science and engineering indicators (NSB-2018-1). Alexandria, VA: National Science Foundation. Retrieved from https://www.nsf.gov/statistics/2018/nsb20181/assets/nsb20181.pdf

Ong, M. (2005). Body projects of young women of color in physics: Intersections of gender, race, and science. Social Problems, 52(4), 593-617.

https://doi.org/10.1525/sp.2005.52.4.593

Oyserman, D., Bybee, D., \& Terry, K. (2006). Possible selves and academic outcomes: How and when possible selves impel action. Journal of Personality and Social Psychology, 91(1), 188.

Pasupathi, M., Stallworth, L. M., \& Murdoch, K. (1998). How what we tell becomes what we know: Listener effects on speakers' long-term memory for events. Discourse Processes, 26(1), 1-25.

Rainey, K., Dounas-Frazer, D. R., \& Huynh, J. (2016). CU-Prime: A student-led community at the University of Colorado Boulder, PERCoGS Newsletter, 7, 67.

Reinholz, D. L., \& Dounas-Frazer, D. R. (2017). Personalized instructor responses to guided student reflections: Analysis of two instructors' perspectives and practices. American Journal of Physics, 85(11), 850-860. https://doi.org/10.1119/1.5002683

Rosa, K., \& Mensah, F. M. (2016). Educational pathways of Black women physicists: Stories of experiencing and overcoming obstacles in life. Physical Review Physics Education Research, 12(2). https://doi.org/10.1103/PhysRevPhysEducRes.12.020113

Sabella, M. S., Mardis, K. L., Sanders, N., \& Little, A. (2017). The Chi-Sci Scholars Program: Developing community and challenging racially inequitable measures of success at a minority-serving institution on Chicago's Southside. The Physics Teacher, 55(6), 350-355. https://doi.org/10.1119/1.4999730

Sabella, M. S., Van Duzor, A. G., \& Davenport, F. (2016). Leveraging the expertise of the urban STEM student in developing an effective LA Program: LA and Instructor Partnerships (pp. 288-291). Proceedings of the 2016 Physics Education Research Conference. Retrieved from https://www.compadre.org/per/items/detail.cfm?ID=14250

Seymour, E., \& Hewitt, N. M. (1997). Talking about leaving: Why undergraduates leave the sciences (Vol. 12). Boulder, CO: Westview Press.

Shah, N. (2017). Race, ideology, and academic ability: A relational analysis of racial narratives in mathematics. Teachers College Record, 119(7), 1-42.

Stets, J. E., Brenner, P. S., Burke, P. J., \& Serpe, R. T. (2017). The science identity and entering a science occupation. Social Science Research, 64, 1-14. https://doi.org/10.1016/i.ssresearch.2016.10.016

Tice, D. M. (1992). Self-concept change and self-presentation: The looking glass self is also a magnifying glass. Journal of Personality and Social Psychology, 63(3), 435. 
Traweek, S. (1988). Beamtimes and lifetimes: The world of high-energy physicists. Cambridge, MA: Harvard University Press.

Woodcock, A., Hernandez, P. R., \& Schultz, P. W. (2016). Diversifying science: Intervention programs moderate the effect of stereotype threat on motivation and career choice. Social Psychological and Personality Science, 7(2), 184-192.

Zaniewski, A. M., \& Reinholz, D. L. (2016). Increasing STEM success: A near-peer mentoring program in the physical sciences. International Journal of STEM Education, 3(1), 14. https://doi.org/10.1186/s40594-016-0043-2 